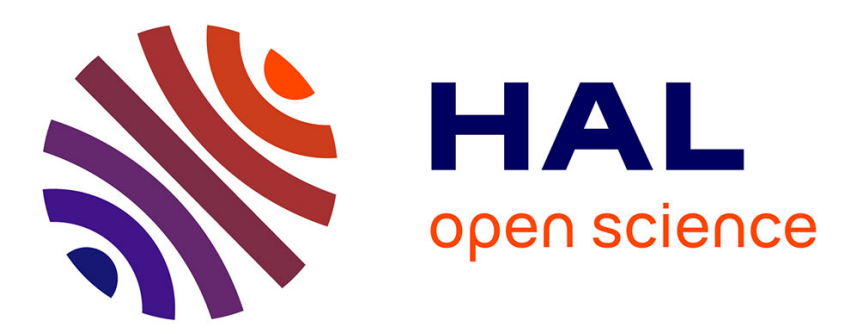

\title{
La synagogue de la Ghriba à Djerba. Réflexions sur l'inclusivité d'un sanctuaire partagé en Tunisie
}

Dionigi Albera, Manoël Pénicaud

\section{To cite this version:}

Dionigi Albera, Manoël Pénicaud. La synagogue de la Ghriba à Djerba. Réflexions sur l'inclusivité d'un sanctuaire partagé en Tunisie. Les Cahiers d'Outre-Mer. Revue de géographie de Bordeaux, 2016, LXIX (274), pp.103-132. 10.4000/com.7881 . hal-03572173

\section{HAL Id: hal-03572173 \\ https://hal-amu.archives-ouvertes.fr/hal-03572173}

Submitted on 14 Feb 2022

HAL is a multi-disciplinary open access archive for the deposit and dissemination of scientific research documents, whether they are published or not. The documents may come from teaching and research institutions in France or abroad, or from public or private research centers.
L'archive ouverte pluridisciplinaire HAL, est destinée au dépôt et à la diffusion de documents scientifiques de niveau recherche, publiés ou non, émanant des établissements d'enseignement et de recherche français ou étrangers, des laboratoires publics ou privés. 
Dionigi Albera et Manoël Pénicaud, «La synagogue de la Ghriba à Djerba. Réflexions sur l'ouverture d'un sanctuaire partagé en Tunisie », Cahiers d'OutreMer. Prier aux Suds. Les lieux de culte entre territorialisations, cohabitations et mobilités du religieux, 274, Presses Universitaires de Bordeaux, 2016 (parution 2018) pp. 103-132.

\author{
Albera Dionigi \\ albera@mmsh.univ-aix.fr \\ Directeur de recherche au CNRS \\ Institut d'ethnologie méditerranéenne européenne et comparative (UMR 7307) \\ Aix-Marseille Université \\ Anthropologue \\ Manoël Pénicaud \\ manoel.penicaud@cnrs.fr \\ Chargé de recherche au CNRS \\ Institut d'ethnologie méditerranéenne européenne et comparative (UMR 7307) \\ Aix-Marseille Université \\ Anthropologue
}

\title{
Résumé :
}

A la fois lieu de culte et lieu saint, la synagogue de la Ghriba sur l'île de Djerba en Tunisie est un sanctuaire fréquenté conjointement par des fidèles juifs et musulmans. Ce type de «partage » relève d'un phénomène attesté dans l'ensemble du Maghreb sur la longue durée, mais qui s'est vu considérablement réduit à la suite de l'émigration progressive des juifs sépharades vers l'Europe et Israël à partir du milieu du $\mathrm{XX}^{\mathrm{e}}$ siècle. A Djerba toutefois, cette mixité interreligieuse a perduré car une communauté juive a subsisté localement jusqu'à nos jours. En 2002, un attentat attribué à Al-Qaïda puis les conséquences de la révolution dite de Jasmin (2011) ont particulièrement limité cette inclusivité, ainsi que le retour ponctuel de ces juifs tunisiens en quête de racines. Le pèlerinage annuel revêt en effet une forte dimension mémorielle et identitaire valorisée par l'État au nom d'une mythique "convivencia ». Plus largement, cet article vise à appréhender cette hétérogénéité interconfessionnelle en questionnant la problématique de l'ouverture de ce sanctuaire emblématique des croisements dévotionnels entre juifs et musulmans au Maghreb.

\section{Mots-clés :}

Pèlerinage, Ghriba, Djerba, Tunisie, synagogue, judaïsme, islam, culte judéo-musulman, lieu saint partagé

\begin{abstract}
:
Both place of worship and holy place, the Ghriba synagogue on the island of Djerba in Tunisia is a sanctuary attended jointly by both Jews and Muslims. This "sharing" is a long term phenomenon attested throughout the Maghreb, but elsewhere has been considerably reduced as a result of the progressive emigration of Jews to Europe and Israel in the mid-twentieth century. However these interfaith crossings have lasted in Djerba since a Jewish community has stayed locally until nowadays. In 2002, an attack imputed to Al-Qaeda and then the consequences of the so-called Jasmin Revolution (2011) further limited this inclusiveness, as well as the punctual return of these Tunisian Jews in search of roots. Indeed the annual pilgrimage has a strong memorial and identity dimension promoted by the State in the name of a mythical "convivencia". More broadly, this article aims at understanding this heterogeneity by
\end{abstract}


questioning the issue of the opening of this emblematic sanctuary of devotional crossings between Jews and Muslims in the Maghreb.

\section{Key-Words :}

Pilgrimage, Ghriba, Djerba, Tunisia, synagogue, Judaism, Islam, Jewish-Muslim Cults

$\underline{\text { NB : les photographies insérées dans ce document sont en basse définition. Les fichiers HD }}$ sont transmis à part. Les photographies sont celles de l'auteur(e)

$\mathrm{Au}$ cours des dernières années, de nombreuses études ont été consacrées à la fréquentation conjointe des mêmes sanctuaires par des fidèles de religions différentes dans l'espace méditerranéen. De cette manière, la vision qui attribue des frontières hermétiquement fermées aux religions monothéistes a été remise en question (Albera et Couroucli, 2009 ; Albera et Pénicaud, 2017 ; Aubin-Boltanski, 2008 ; Barkan et Barkey, 2014 ; Bowman, 2012 ; Depret et Dye, 2012). Ces travaux récents s'inscrivent notamment dans l'héritage intellectuel du savant anglais Frederick William Hasluck (1878-1920), qui dans les premières décennies du XXe siècle avait montré que les relations entre les groupes religieux de l'Empire ottoman tendaient à être symbiotiques. Chrétiens et musulmans étaient prêts à adresser leurs demandes aux sanctuaires administrés par l'autre religion, si ces derniers jouissaient d'une réputation d'efficacité. Même si son travail concernait l'interaction entre chrétiens et musulmans, Hasluck a également documenté plusieurs exemples dans lesquels la présence interreligieuse dans le même sanctuaire concernait les juifs (Hasluck, 2000). Les explorations récentes ont corroboré et enrichi cette vision. Au cours des siècles, le paysage méditerranéen apparait ainsi ponctué par des milliers de lieux saints marqués, souvent pendant de longues périodes, par l'interpénétration de traditions différentes.

La plupart des pèlerinages partagés associent chrétiens et musulmans dans des lieux appartenant à l'une ou à l'autre religion. Plusieurs formes de fréquentation commune concernent cependant, selon les lieux et les époques, les juifs et les musulmans, comme dans le cas des cultes judéomusulmans particulièrement répandus au Maghreb. Cette situation a été bouleversée par le départ massif des juifs sépharades d'Afrique du Nord dans la seconde moitié du $\mathrm{XX}^{\mathrm{e}}$ siècle. Les pèlerinages judéo-musulmans ont presque entièrement disparu, sauf dans une poignée de cas au Maroc et en Tunisie, dont celui de Djerba, sur lequel nous allons concentrer notre attention, constitue sans doute l'un des exemples les plus significatifs à l'échelle du Maghreb (Allagui, 2016 ; Ben Ami, 1990 ; Voinot, 1948 ; Zafrani, 1990).

Un premier objectif de cet article sera de suivre les vicissitudes de ce pèlerinage pendant plus d'un siècle, en l'abordant sous l'angle de la fréquentation interreligieuse. La hiloula de la Ghriba à Djerba est un phénomène connu et a fait déjà l'objet d'études importantes (Valensi et Udovitch, 1984). Cependant, la dimension du partage et de l'hétérogénéité confessionnelle a été peu explorée, mis à part un article qui a esquissé quelques pistes sans véritable ethnographie (Carpenter-Latiri, 2012) et un second qui sert notamment de base à la présente étude (Albera, 2015). Nous allons ici montrer que le caractère pluriel de ce pèlerinage se maintient depuis le début du XXe siècle jusqu'à nos jours, malgré les difficultés de plus en plus sérieuses liées au contexte politique national et international.

Le second objectif consiste à réaliser une radiographie approfondie du pèlerinage, en isolant ses principaux éléments constitutifs. Pour cela nous nous appuierons sur des sources historiques variées, et surtout sur une enquête ethnographique directe menée en 2014. Le pèlerinage de la

\footnotetext{
${ }^{1}$ Signifiant «crier avec joie et crainte» en hébreu, le terme hiloula désigne l'acte de visiter rituellement et collectivement les tombes de rabbins considérés comme Tzaddikim (justes).
} 
Ghriba constitue un ensemble particulièrement complexe. Cette synagogue est à la fois un lieu de culte régulier pour une communauté locale et un lieu saint attirant des pèlerins venant de loin (et appartenant aussi à une autre religion). Nous analyserons les discours qui la concernent, en montrant qu'ils constituent une polyphonie articulée, où se côtoient des tendances exclusives et inclusives. Nous procéderons en outre à un examen serré des pratiques rituelles, dans le but de déterminer les domaines d'action respectifs des juifs et des musulmans, et de déceler ce qui est propre seulement à un groupe et ce qui est commun. Plus largement, il s'agira de saisir un croire en actes, matérialisé dans des gestes qui ne se cantonnent pas au répertoire stabilisé d'une religions donnée, mais s'ouvrent sur une forte inventivité rituelle. Cela constitue le terrain d'une interreligiosité pratique, encore peu théorisée, mais vécue à travers l'espoir qui anime un investissement croyant, et exprimée surtout par une piété corporelle et tactile.

Sur le plan méthodologique, cet article repose à la fois sur une enquête ethnographique nourrie par une collecte filmique et photographique - approche qui enrichit considérablement l'analyse après l'enquête sur le terrain (Pénicaud, 2014) -, ainsi que sur une approche diachronique grâce à l'existence de nombreuses sources historiques allant de la fin du XIX $\mathrm{X}^{\mathrm{e}}$ siècle à nos jours. Cela permet donc de rendre compte des mutations et de retracer le développement de ce lieu saint partagé dont l'ambiguïté apparaît un élément constitutif (Hasluck, 2000 ; Hobart et Zarcone, 2017). Cette notion ne doit pas être entendue ici comme synonyme de désordre et de manque de clarté, mais comme la manifestation d'une richesse de contenus et d'expérimentations rituelles qui se glissent dans les interstices consentis par l'ordre religieux établi (Albera, 2017).

\section{Deux récits de fondation divergents}

La Ghriba de Djerba s'inscrit dans une configuration plus vaste, qui a été mise en lumière il y a plus d'un siècle par Nahum Slouschz, orientaliste de grande érudition et fervent sioniste, qui, dans les premières décennies du $\mathrm{XX}^{\mathrm{e}}$ siècle, visita les différentes régions du Maghreb - de la Lybie au Maroc - pour documenter les conditions de vie des juifs qui y habitaient et pour déceler les traces historiques et archéologiques de leur passé. Lors de ses explorations, il isola une typologie de synagogues présentes en Lybie, Tunisie et Algérie, marquées par une appellation identique - Ghriba - et par une fréquentation élargie aux musulmans. Le terme arabe ghriba signifie « étrangère », "solitaire », mais aussi « mystérieuse » (Albera, 2015). Slouschz identifia six synagogues de ce type, et avança des hypothèses historiques quant à leur origine. A son avis, il ne s'agissait pas de simples synagogues, mais de sanctuaires dont l'origine remontait «à des temps reculés » et même à une époque anté-islamique (Slouschz, 1909 : 347-348). Au moment de la conquête arabe, il aurait existé en Afrique du Nord un certain nombre de sanctuaires juifs entretenus par des groupes de Cohenim (prêtres d'origine aaronide), dont les prototypes étaient les temples d'Éléphantine et de Léontopolis en Égypte, qui, dans l'Antiquité, avaient défié le monopole de celui de Jérusalem. Les arguments avancés par Slouschz demeurent très hypothétiques. Il s'appuie notamment sur les étiologies locales, qui font parfois remonter la fondation des sanctuaires à une époque biblique. En Lybie, en face de la Ghriba du Djebel Iffren, il avait repéré un village qui portait le nom de Cohen, tandis qu'à Djerba, la Ghriba se trouve à proximité de l'un des deux villages juifs de l'île, Hara Sghira, habité majoritairement par des Cohenim. Le fait que certaines Ghribas du Maghreb se trouvent à l'extérieur des centres habités (ce qu'il lie à l'appellatif de « solitaire ») renvoie également, à son avis, à une sacralité qui rappelle celle de l'ancien Temple. La vénération que les populations musulmanes avaient pour ces sanctuaires montrerait à son tour leur origine antéislamique, en étant comme un legs de la période au cours de laquelle les Berbères étaient ouverts aux influences juives. La vision de Slouschz s'inscrivait dans l'aspiration qui poussait alors des intellectuels sionistes à identifier des essaims du judaïsme ancien (comme dans le cas des Falacha d'Éthiopie). Ses audacieuses hypothèses historiques ne s'appuyaient que sur des bases 
assez minces et il serait hasardeux de les adopter. Cependant, au-delà de leurs limites, elles ont le mérite de souligner l'existence d'une trame reliant les différentes Ghriba du Maghreb.

Un récit présent dans la communauté sépharade de Djerba indique que des prêtres juifs (cohenim) fuyant la Palestine après la destruction du Temple de Jérusalem en 586 avant notre ère par l'armée de Nabuchodonosor, accostèrent sur cette île qui leur parut "étrange » et « mystérieuse ». Décidant de s'y installer, ils y fondèrent leur synagogue en y encastrant des pierres provenant d'une porte du Temple qu'ils avaient pu emporter avec eux ${ }^{2}$. Cette légende a été publiée pour la première fois dans un livre du rabbin Abraham Haim Addadi de Tripoli, imprimé à Livourne en 1849. Elle a été par la suite détaillée par Nahum Slouschz qui l'avait collectée sur place au début du $\mathrm{XX}^{\mathrm{e}}$ siècle.

Vers la fin du XIXe siècle un voyageur européen avait recueilli une variante de cette légende : à la Ghriba, écrit-il, " des prêtres barbus et solennels, coiffés comme les sphinx d'un bandeau rouge tombant sur les épaules à l'égyptienne, gardent les Tables de la Loi que Moïse reçut au Sinaï des mains de Jéhovah. Je ne les ai point vues, ni aucun Juif de l'île, mais les prêtres assurent qu'elles sont dans le sanctuaire ». Ces derniers affirment aussi qu'un puits situé dans la cour de la synagogue communiquerait avec celui du Temple de Jérusalem (Amaury, 1896 : 396).

L'auteur d'une description géographique de l'île du début du $\mathrm{XX}^{\mathrm{e}}$ siècle reprend le même thème, en observant qu'une légende prétend que «une table de Moïse » aurait été trouvée sur l'emplacement de la synagogue (Gendre, 1908: 78). Le même auteur ajoute tout de suite d'autres éléments significatifs, qui vont dans une autre direction : «La synagogue doit son nom à une jeune fille pauvre, étrangère, qui vécut à Djerba et dont la sainteté était reconnue de tous, même des musulmans. " Il s'agit là du noyau d'un second récit local, relaté de manière plus développée également par Slouschz. Une jeune femme "étrangère », "solitaire » et " mystérieuse » serait venue un jour s'installer dans une hutte de branches, sur une colline déserte, à proximité de Hara Sghira. Les habitants se montrent distants face à cette femme «mystérieuse », et personne n'ose l'approcher. Mais une nuit, sa cabane prend feu; les villageois pensent qu'elle s'adonne à des pratiques de magie et ne viennent pas à son secours ; le lendemain, ils découvrent son corps sans vie mais intact. Ils comprennent alors qu'il s'agissait d'une sainte et décident d'élever un sanctuaire à cet endroit précis. Le portrait de la jeune femme mystérieuse ne fait aucune mention de sa religion, si bien qu'à partir de cette indétermination, certains considèrent qu'elle ait pu être juive ou musulmane.

On voit bien comment ces deux récits offrent deux visions opposée quant aux origines du sanctuaire. La première met l'accent sur son caractère juif - en liant directement la fondation de la Ghriba au Temple de Jérusalem, pivot symbolique du judaïsme - et sur son origine illustre et lointaine (dans le temps et dans l'espace), qui le relie à des épisodes fondateurs de l'histoire biblique. La seconde met en exergue la dimension locale et le caractère indéterminé de la chronologie de la fondation du sanctuaire et même de l'inscription religieuse de la figure fondatrice. Notre enquête à Djerba suggère que, encore aujourd'hui, les deux registres peuvent cohabiter et être tour à tour mobilisés dans le discours local selon les occasions, les interlocuteurs et leurs objectifs. Lorsqu'il est question de promouvoir le pèlerinage et d'asseoir son prestige, les arguments historiques sont mis en avant, ce qui permet d'accentuer la sacralité du sanctuaire en soulignant une parenté directe avec le saint des saints du judaïsme. Une telle filiation érige et légitime l'exceptionnalité de la Ghriba, dans le temps mythique de cette diaspora $\mathrm{du} \mathrm{VI}^{\mathrm{e}}$ siècle avant notre ère. Ajoutons que l'opinion selon laquelle les pierres ramenées de Jérusalem ne seraient autres que les Tables de la Loi - ce qui revient à voir dans cet édifice une substitution du Temple - trouve encore aujourd'hui ses adeptes (Allali, 2014 : 324-329). En revanche, le récit inclusif, centré sur la jeune femme, domine aujourd'hui parmi

\footnotetext{
${ }^{2}$ D'où l'autre nom de Hara Sghira : Dighet, qui serait une déformation berbère de l'hébreu dilet, désignant la porte
} 
les pèlerins, avec des variantes qui dénotent une sorte de bricolage mythologique. En 2014, une dame juive, rencontrée dans la synagogue, expose sa version comme suit :

«La Ghriba, ça veut dire "la solitaire" en arabe et en juif (sic). On dit que c'était une jeune fille qu'on a trouvée sur la plage. Les Tunisiens musulmans ont dit que c'était une fille de chez eux, et les juifs d'ici ont dit que c'était une fille de chez eux. Donc, ils ont construit une synagogue où on entre comme dans une mosquée, la tête couverte et pieds nus. »

La polarisation qui émerge de l'examen du corpus légendaire innerve plus généralement les pratiques religieuses liées à ce sanctuaire. On dirait qu'elle détermine un champ où les contraires peuvent coexister et trouver des formes de conciliation.

\section{La synagogue aux XIXe et XXe siècles}

Les narrations locales et les spéculations de Slouschz sur une origine très ancienne des juifs djerbiens (et de leur Ghriba) se heurtent au manque de sources historiques pour les époques plus reculées. Ce sont des documents de la Genizah du Caire, datant du XI ${ }^{\mathrm{e}}$ siècle, qui fournissent le premier témoignage historique de l'existence sur l'île d'une communauté juive, alors bien engagée dans le commerce méditerranéen. Un peu plus tard, Maïmonide dresse un portrait peu flatteur des juifs de Djerba, dont il critique les opinions, les croyances et les pratiques, surtout en matière de «pureté » rituelle. Un témoignage significatif de la continuité et de l'importance de l'implantation juive dans l'île vient d'une carte italienne de 1560, dans laquelle les seuls lieux habités mentionnés sont deux villages juifs. Même par la suite la population juive a conservé sa concentration en deux haras (terme arabe désignant les quartiers juifs en Afrique du Nord), villages qui sont restés exclusivement juifs jusqu'au $\mathrm{XX}^{\mathrm{e}}$ siècle. Il s'agit de Hara Sghira (« petit quartier ») aussi appelée Dighet, non loin de la Ghriba, et Hara Kbira ("grand quartier ») à six kilomètres au nord. Dans le cas de Djerba, il ne s'agit pas de quartiers d'une même ville, mais de véritables bourgades, ce qui constitue un cas unique au Maghreb (Taïeb, 2000 : 99). Tout en étant liés, les deux villages présentent également des oppositions structurelles, qui se traduisent par des mythes d'origine différents. Les habitants de Hara Sghira se disent arrivés de Palestine après la destruction du Premier Temple au $\mathrm{VI}^{\mathrm{e}}$ siècle A.C., tandis que ceux de Hara Kbira se revendiquent d'une émigration bien plus récente depuis la péninsule ibérique. Dans l'ensemble, les juifs de Djerba représentent une des communautés les plus importantes sur la totalité de la population israélite de Tunisie. Le premier recensement de la population « indigène » tunisienne, effectué en 1921, indique que, avec ses 3000 habitants, elle constituait la plus importante implantation juive en dehors de l'agglomération tunisoise (Sebag, 1991 : 136-137). Au cours des décennies qui suivent, la population juive de l'île connaît une croissance importante puisqu'à la fin des années 1940, l'île de Djerba compte 4500 juifs et une vingtaine de synagogues ${ }^{3}$.

En dépit des allégations sur son enracinement immémorial, les témoignages matériels ne traduisent pas une grande ancienneté de la synagogue de la Ghriba. Plusieurs voyageurs perçoivent le décalage entre des récits éblouissants et une réalité assez modeste et ordinaire. Vers la fin du XIX ${ }^{\mathrm{e}}$ siècle, Vincent Amaury remarque : "En dépit des souvenirs de la terre de Judée, dont on ne peut malheureusement constater l'authenticité, j'ai trouvé à la synagogue de l'Hagriba l'aspect des autres mosquées (sic), et la salle de prière n'offre non plus rien de remarquable, si ce n'est la coutume que l'on a de faire prêter serment, en cas grave, devant la porte du Saint de Sait (sic) interdit au profane. Tout parjure, dit la légende, meurt dans

\footnotetext{
${ }^{3}$ Les effectifs de la population juive dans l'ensemble de la Tunisie vont d'environ 50000 en 1921 à environ 70000 en 1946.
} 
l'année » (1896:396 $)^{4}$. En 1906, lors de son séjour à Djerba, Nahum Slouschz visite la Ghriba en compagnie des notables de Hara Sghira, dont il vient d'écouter les récits qui faisaient remonter la fondation du sanctuaire à la plus haute antiquité. On peut imaginer son impatience lorsqu'il parcourt avec un cortège de dignitaires locaux le court itinéraire vers la synagogue, entouré, dit-il, de jasmins. Au bout du chemin, il découvre un petit bâtiment, surmonté par une modeste coupole qui lui paraît de construction récente. Il entre dans le vestibule, qui avait été rajouté récemment à l'ensemble, où dix hommes âgés, des Asarah Batlanim, récitent des passages du Zohar et des Psaumes. L'intérieur du sanctuaire confirme son impression précédente. Il n'y découvre rien de remarquable et de singulier. Il s'agit, écrit-il, d'une synagogue africaine assez typique, avec ses colonnes byzantines arabisées, dépourvue d'une décoration particulière. Il cherche des traces d'un passé plus ancien, il explore les manuscrits qui y sont conservés, mais le plus vieux qu'il déniche remonte tout au plus au XVII ${ }^{\mathrm{e}}$ siècle. Bref, la moisson de cette visite est plutôt insatisfaisante par rapport à ses ambitions de repérer les traces du passé mythique du judaïsme djerbien, comme il le constate avec amertume : « Je quittai la synagogue un peu insatisfait. C'était effectivement intéressant d'entendre ces bonnes gens parler de traditions remontant aussi loin qu'à Esdras ; mais au-delà de leur discours, il n'y avait pas une seule trace de ces traditions » (Slouschz, $1927: 265)^{5}$. En effet, l'architecture de la Ghriba ne dévoile pas d'indices d'un passé très éloigné. Les ajouts et les rénovations suggèrent plutôt une expansion du sanctuaire à partir de la seconde moitié du $\mathrm{XIX}^{\mathrm{e}}$ siècle, en lien avec son rayonnement grandissant. Une quarantaine d'années avant sa visite (entre 1860 et 1870) le bâtiment avait été reconstruit. L'addition du vestibule semble encore plus récente. Lors de sa visite, Slouschz remarque également le chantier en cours pour la construction de logements pour les pèlerins malades venant de loin, y compris d'Égypte et du Maroc, attirés par les propriétés miraculeuses du sanctuaire. Tout semble en somme confirmer le succès croissant de la Ghriba.

Par la suite le décor intérieur sera enrichi et le vestibule (construit apparemment peu avant la visite de Slouschz sur l'emplacement d'une cour ouverte) devient une salle en soi. Des travaux importants ont lieu en particulier vers 1920, comme le remarque Véhel :

"La millénaire Gheriba djerbienne menaçait de s'effondrer il y a dix ans sous l'effet de l'âge. Pour réparer des ans le réparable outrage, une souscription circula dans l'île et une nouvelle Gheriba, belle, vaste, aérée, pittoresque à souhait, aux enluminures bizarres et aux boiseries artistiquement orientales, d'une architecture arabo-byzantine, surgit de terre. Les photographies, les cartes postales, les revues illustrées, et jusqu'au cinéma, ont projeté au loin l'éclat de sa joliesse et de la ferveur de ses fidèles. Des bacs courent le long des murs (nouveauté !), tandis que les vieillards qui ne se résolvent pas aux manières modernes continuent à avoir leurs nattes de paille posées à même le sol et à s'asseoir 'en tailleur'» (Véhel, $1930: 208)$.

Dans les années 1950, d'autres travaux d'élargissement concerneront l'espace pour loger les pèlerins, en particulier ceux provenant de Libye (Valensi et Udovitch, 1984 : 128). Cependant ces nouveaux locaux ont été peu utilisés, car l'afflux des pèlerins libyens s'est bientôt tari, à la suite de leur émigration massive vers Israël ou l'Italie. Au cours des dernières décennies les modalités du pèlerinage ont, en tout cas, changé. Les pèlerins venant d'ailleurs séjournent de plus en plus dans des hôtels touristiques situés sur la côte, et l'espace du caravansérail n'est désormais plus utilisé pour héberger les voyageurs.

\footnotetext{
${ }^{4}$ Ce rôle est également attesté pour la Ghriba d'Annaba : « Le plus grand serment que pourrait faire un juif pieux du Nord de l'Afrique est celui-ci : 'Je le jure pour la Gheriba de Bône' » (Véhel, 1930 : 209).

${ }^{5}$ "I left the synagogue a little unsatisfied. It was indeed interesting to hear these good people talk about traditions going back as far as Esdras; beyond their talk there was not a single trace of these traditions. »
} 


\section{Lieu de culte et lieu saint}

Pour saisir la complexité de la configuration de la Ghriba, il faut établir une distinction d'ordre général entre lieu de culte et lieu saint. Le premier type correspond à l'espace de la pratique religieuse collective, régulière et routinière (synagogue, église, mosquée); le second est par contre marqué par une sacralité plus dense qui suscite une pratique ponctuelle voire exceptionnelle, dans l'espace-temps singulier du pèlerinage. Or l'ambiguïté de la Ghriba est de relever de ces deux registres. Au cours de toute son histoire documentée, la synagogue de la Ghriba manifeste en somme une double nature. D'un côté, elle est un lieu de culte à caractère local, étroitement lié à Hara Sghira. Elle est même la seule synagogue de cette agglomération qui renferme des rouleaux de la Torah. Comme toute synagogue, la Ghriba est un lieu de prière, d'étude et d'assemblée pour les hommes de la bourgade. De l'autre côté, la Ghriba est un centre de pèlerinage au rayonnement international.

En tant que lieu de culte, la Ghriba est un espace uniquement masculin. En tant que lieu saint, et surtout au moment du pèlerinage, la synagogue devient un espace mixte, majoritairement investi par les femmes qui sont les protagonistes de nombreux rituels, souvent liés à la fécondité. Plus récemment la Ghriba est aussi devenue un lieu touristique, en se transformant en une étape des circuits de découverte de l'île (une modalité de visite que l'on retrouve par ailleurs dans un grand nombre de lieux saints).

Un aspect distinctif témoigne du statut singulier de cette synagogue : il faut se déchausser pour entrer dans la seconde salle qui marque la centralité du sanctuaire. Cet aspect est déjà évoqué par Slouschz, à qui ses hôtes demandent d'ôter ses chaussures pour pouvoir accéder à l'espace interne de la synagogue. Dans son récit, il relie simplement cela à la coutume musulmane («after the Mussulman fashion », dit-il, p. 272). Curieusement, il ne fait pas appel à une argumentation qui aurait pu aller dans le sens de sa quête d'une origine antique de la Ghriba. En effet le déchaussement renvoie aux usages présents dans le Temple de Jérusalem, et plus généralement à la rencontre avec le sacré, par exemple dans l'épisode biblique du Buisson ardent (Exode $3: 5$ ). Comme nous l'avons déjà mentionné, des pèlerins contemporains que nous avons rencontrés formulent à leur tour le même lien avec la tradition musulmane, en mettant cela en relation avec le caractère indéterminé de la figure de la Ghriba.

\section{Le temps fort du pèlerinage (hiloula)}

Si la Ghriba vit toute l'année sa double existence de lieu de culte et de lieu saint, elle est marquée par un moment culminant qui se manifeste à l'occasion du pèlerinage annuel. Déjà au début du $\mathrm{XX}^{\mathrm{e}}$ siècle, Slouschz compare la Ghriba de Djerba à l'un des plus importants centres de pèlerinages européens. A ses yeux il s'agit en effet d'une sorte de « Lourdes juive ». Par la suite, le pèlerinage annuel semble connaître encore une accentuation de son rayonnement. Dans l'entre-deux-guerres on fait venir des musiciens de Tunis, mais aussi du Caire et d'Alexandrie. Des bateaux sont affrétés pour acheminer les pèlerins depuis les ports de Tunisie, de Tripolitaine, d'Égypte, de Grèce. En 1930, Jacques Véhel fournit une description de ce pèlerinage foisonnant, en le comparant lui-aussi avec celui de Lourdes : "Pendant plusieurs jours, ce ne sont que processions, chants sacrés, offices successifs, illuminations, plantureuses agapes, accolades fraternelles, musiques incessantes, brouhaha des grands jours, fêtes inoubliables, qui semblent renouvelées des Mille et une Nuits. C'est un 'Lourdes' oriental, dans un décor de rêve, une atmosphère de joie sincère, un étincellement de vêtements criards et de bijoux massifs, parant les femmes de l'île, qui ont gardé jalousement leur costume indigène, si inattendu, si seyant, si éloigné de nos 'dernières modes de Paris'» (1930 : 208).

Les festivités débutent le 14 du mois d'Iyar, en commémoration de Rabbi Meïer Baal Haness, 
jusqu'au 18 qui correspond à la fête (hiloula, en hébreu) du Lag Ba'Omer ${ }^{6}$ Cette date célèbre notamment la montée de l'âme du rabbin Shimon Bar Yohaï (appelé "Rabbi Shim'un» localement), l'auteur supposé du Zohar, connu en français sous le nom de Livre des Splendeurs. Même s'il est inhumé à Méron en Israël, cette date donne lieu à des hiloulot sur la tombe d'autres Justes (tsaddikim) qui jouissent d'une aura de sainteté. La date du pèlerinage de Djerba s'inscrit donc dans une tradition qui dépasse largement les frontières de la Tunisie.

$\mathrm{Au}$ cours de la première moitié du $\mathrm{XX}^{\mathrm{e}}$ siècle, la Ghriba de Djerba semble posséder tous les traits d'un important pôle régional de pèlerinage. Elle attire des pèlerins qui proviennent non seulement de son principal bassin d'influence - le Sud tunisien, la Lybie - mais aussi de contrées plus éloignées (Égypte, Grèce). A l'occasion de ce rendez-vous annuel, le pèlerinage permet ainsi de ressouder un vaste conglomérat de communautés juives d'Afrique du Nord, et même au-delà. La seconde moitié $\mathrm{du} \mathrm{XX}^{\mathrm{e}}$ siècle voit une transformation progressive du contexte du pèlerinage. La population juive d'Afrique du Nord connaît une diminution vertigineuse, au point de disparaître en l'espace de quelques décennies, en Algérie, Lybie et Égypte. Même la population juive de Djerba connaît un déclin progressif, suite aux départs massifs vers Israël et vers la France. Bien que réelle, cette émigration n'a pas conduit à la disparition totale de la présence juive. Certes celle-ci est aujourd'hui affaiblie, mais l'île abrite encore l'une des plus grandes communautés israélites du Maghreb, composée d'environ 900 personnes, habitant principalement dans les deux villages déjà cités : Hara Sghira et Hara Kbira. Une telle concentration est importante quand l'on sait que la Tunisie compte de nos jours seulement 1600 à 1700 juifs. Cette subsistance d'une communauté endémique peut en partie s'expliquer par la qualité d'isolat qui a également profité au maintien jusqu'à nos jours d'une communauté ibadite, liée à ce que l'on appelle parfois la troisième famille de l'islam. Les juifs de Djerba étaient également connus pour leur conservatisme et leur attachement aux traditions ancestrales. Toujours est-il que l'insularité a favorisé leur maintien et a facilité le voisinage interconfessionnel.

\section{Pèlerinage du retour et crainte des attentats}

$\mathrm{Au}$ cours des dernières décennies du $\mathrm{XX}^{\mathrm{e}}$ siècle, le pèlerinage s'est perpétué, mais il a changé partiellement de configuration. Les communautés d'Afrique du Nord qui y participaient se sont réduites à peau de chagrin. La plus gros contingent de pèlerins est constitué de juifs tunisiens émigrés en Europe ou en Israël. De cette manière, le pèlerinage est de plus en plus devenu un lieu de retrouvailles temporaires de la diaspora juive tunisienne. Se rendre à Djerba à l'occasion de la fête du Lag Ba'Omer équivaut aussi à renouer temporairement avec ses racines (rites, langue, musique, nourriture, etc.). L'espace-temps du pèlerinage permet la reconstruction éphémère d'une communauté innervée par le ciment de la pratique religieuse et par l'effervescence festive (Valensi et Udovitch, 1984). De plus, force est d'observer une hybridation des pratiques de pèlerinage et du tourisme de masse (recours aux agences de voyage, séjour dans les hôtels de luxe, par exemple) ${ }^{7}$. Toutefois, cette combinaison est loin d'être propre à la Ghriba. Comme l'ont montré de nombreux travaux, la dichotomie entre touriste et pèlerins ne va pas de soi dans la pratique et n'est que conceptuelle (Badone et Roseman, 2004). Dès la fin des années 1970, les anthropologues Édith et Victor Turner déclaraient : «Un touriste est à moitié pèlerin, si un pèlerin est à moitié un touriste » (Turner et Turner, 1978) $)^{8}$.

\footnotetext{
${ }^{6} \mathrm{Le}$ Lag Ba'Omer advient trente-trois jours après celui de l'Omer, lui-même célébré au lendemain du début de la Pâque juive (Pessa'h).

${ }^{7}$ Notons que le directeur de l'une des plus importantes agences de voyage est également membre du comité d'organisation de la hiloula, de même que d'autres membres de sa famille, laquelle joue de ce fait un rôle déterminant.

${ }^{8}$ « A tourist is half a pilgrim, if a pilgrim is half tourist. »
} 
Le retour dans une terre que l'on a quittée souvent précipitamment - en partie à cause d'un sentiment d'insécurité - nécessite de dépasser une double difficulté : la mémoire du déracinement et les menaces actuelles concernant la présence juive dans les pays musulmans. Les turbulences de la géopolitique méditerranéenne se sont invitées dans la synagogue de Djerba. Le sanctuaire a été à plusieurs reprises tragiquement travaillé par les tensions d'un environnement politique envenimé par le conflit israélo-palestinien et par la montée du terrorisme islamiste. En 1985, un soldat tunisien chargé de la sécurité de la Ghriba a ouvert le feu dans le sanctuaire, y faisant cinq morts. Après une période de crise et de peur, où le retour des juifs de Tunisie en pèlerinage semblait compromis ${ }^{9}$, la fête annuelle de la Ghriba a repris de l'ampleur. Au début des années 2000, le pèlerinage attirait plusieurs milliers de pèlerins, jusqu'à 10000 d'après les organisateurs actuels, dont 3000 venus d'Israël. Cet engouement est d'ailleurs bien décrit par un chercheur israélien, Shlomo Deshen, qui étudie ce pèlerinage foisonnant au milieu des années 1990 (Deshen, 1997) ainsi que par la française Sylvia Conord qui relate «de l'intérieur» le voyage de femmes juives de la communauté de Belleville (Conord, 2010). Mais un tournant tragique interrompt soudainement cette expansion. Le 11 avril 2002, à quelques semaines de la fête de Lag Ba'Omer, un attentat-suicide attribué à l'organisation Al-Qaïda provoque la mort de 19 personnes dont 14 touristes allemands, devant l'entrée de la synagogue. Depuis lors, le sanctuaire connaît une importante protection de la part des autorités.

Avec la chute du régime du Président Zine el-Abidine Ben Ali en janvier 2011, le pays entier est plongé dans une période de troubles. En mai de cette année-là, les autorités ont imposé de ne pas organiser le pèlerinage. Celui-ci n'a finalement lieu qu'à l'échelle locale, sans ouverture internationale. L'année suivante, avec l'accession au pouvoir des islamistes du parti politique Ennahdha, l'édition du pèlerinage est particulièrement réduite, beaucoup de pèlerins étrangers décidant de ne pas s'y rendre. Un nouveau tournant s'opère à partir de janvier 2014 avec l'adoption de la nouvelle constitution qui garantit notamment la liberté de culte et la reconnaissance des minorités religieuses, tandis que les islamistes connaissent un net recul. Le contexte politique ayant évolué, un millier de pèlerins juifs reviennent de l'étranger (le double de 2013), surtout de France et d'Israël. Les années suivantes, on constate une nouvelle baisse de fréquentation, notamment à la suite des attentats perpétrés au Musée du Bardo à Tunis en mars et sur une plage de Sousse en mai 2015. Là encore, les pèlerins extérieurs ont craint des menaces d'attentat qui circulaient notamment sur les réseaux sociaux. En effet, des informations émises par le gouvernement israélien ont fait état de risques d'attaques terroristes, ce qui, malgré les démentis du ministère tunisien, a dissuadé de nombreux pèlerins. Dans ce contexte de plus en plus tendu, le pèlerinage semble pourtant redevenir attractif et traversé par une forme de résilience collective.

Les menaces liées la sécurité des pèlerins, l'appareil de protection qui est déployé sur place, les discours politiques qui s'invitent dans le pèlerinage (allant d'une présentation de l'arrivée des pèlerins juifs comme une vitrine de la convivencia tunisienne aux polémiques politiques concernant l'arrivée de citoyens israéliens), la présence à la Ghriba des autorités tunisiennes et des représentants officiels de plusieurs États étrangers, tout cela contribue encore à complexifier le cadre d'une manifestation déjà structurellement composite. Nous allons tenter de démêler quelques fils de cette configuration, en nous appuyant sur une description de la situation actuelle, issue de l'observation du pèlerinage de 2014.

Cela nous permettra aussi d'aborder la question de la perméabilité de la Ghriba par rapport à son environnement musulman. Si des murs symboliques se dressent pour protéger l'identité et l'intimité de cet espace, il existe également des ouvertures qui permettent une certaine

\footnotetext{
${ }^{9}$ Suite à cet attentat, un pèlerinage tunisien de substitution a été créé en France, à Sarcelles, voir Podselver, 2001.
} 
circulation. Nous avons déjà évoqué certains aspects à travers les mythes de fondation de la synagogue et la pratique de se déchausser. Il est temps de nous concentrer sur un élément capital: la mixité confessionnelle entre juifs et musulmans. Si la double fréquentation est mentionnée depuis au moins le début du $\mathrm{XX}^{\mathrm{e}}$ siècle, la présence musulmane est souvent évoquée mais peu étudiée. Déjà au début du $\mathrm{XX}^{\mathrm{e}}$ siècle, lorsque Slouschz présente la Ghriba comme une « Lourdes juive », il ajoute qu'elle attire non seulement de nombreux pèlerins juifs, mais également ses dévots musulmans et même chrétiens (Slouschz, 1909 : 264). Les auteurs successifs notent en général que les musulmans reconnaissent le caractère sacré de la Ghriba, mais ils donnent peu d'informations détaillées sur les modalités de cette attraction. Valensi et Udovitch décrivent par exemple la présence musulmane lors du pèlerinage surtout dans le cadre de la procession qui clôt la journée, mais dans leurs pages, comme en général dans les autres descriptions ethnographiques, l'attention est presque uniquement braquée sur la composante juive. Nous allons au contraire ébaucher une description qui prenne en compte l'affluence bigarrée sur le plan des appartenances religieuses. Dans le compte-rendu des pratiques rituelles qui traversent l'espace-temps du pèlerinage nous mettrons en exergue ce qui est propre seulement aux juifs et ce qui est commun aussi aux musulmans.

\section{Chronique d'un pèlerinage}

À l'approche de la fête du Lag Ba'Omer, les visiteurs se font de plus en plus nombreux. Des tour-opérateurs proposent un «pèlerinage organisé» d'une semaine aux juifs d'origine tunisienne vivant à l'étranger, occasion de conjuguer tourisme balnéaire et pèlerinage. Ces « clients » portent un bracelet pour être facilement identifiés et sont logés dans un hôtel de la zone touristique placé sous haute protection. Après les journées passées au sanctuaire, ils se retrouvent lors de soirées festives et musicales, autre vecteurs de convivialité et de commensalité. Ils rejoignent la Ghriba en autocars spécialement affrétés pour l'occasion et sous le contrôle des forces de police. Le temps du pèlerinage est aussi exceptionnel sur le plan sécuritaire. En contrebas du sanctuaire, tous les véhicules sont tenus de se garer et les visiteurs doivent passer à pied par un portique de sécurité et se soumettre à un contrôle d'identité et à une fouille.

L'ambiance change une fois franchi le mur d'enceinte recouvert à la chaux. La plupart des visiteurs manifestent leur joie d'être arrivés au terme de leur pèlerinage. Une forme d'excitation règne et atteint son comble les jours les plus importants, notamment le vendredi et le dimanche de la semaine concernée. L'espace se distribue de part et d'autre d'une allée centrale : à gauche vers la synagogue (où se déploient les activités concernant la sphère « sacrée »), à droite vers l'ancien caravansérail (réservé à des activités plus « profanes » : cf. infra). Ces deux zones sont perméables du fait de la constante mobilité des pèlerins.

L'espace synagogal s'ouvre sur une première grande salle de prière, haute de plafond et cernée d'un lanterneau, ornée de lustres, de très beaux carreaux de zelliges et d'arches en ogive de couleur bleue ${ }^{10}$. C'est là que des rabbins assis sur des bancs de bois lisent des textes religieux et reçoivent les visiteurs qui leur demandent de réciter des bénédictions pour eux, selon une intonation et un phrasé précis, parfois ponctuées de geste de dévotion. En dehors du pèlerinage, le calme est de mise. Mais pendant la fête, cette salle grouille d'une activité croissante dès le début de matinée. Les rabbins sont plus sollicités que d'habitude et aussi beaucoup photographiés par les visiteurs comme par les journalistes. Ces derniers sont en effet très nombreux chaque année à venir « couvrir l'événement ». Très visible, leur présence s'estompe progressivement au fur et à mesure que les pèlerins entrent par dizaines. Une forme d'effervescence religieuse et conviviale augmente d'heure en heure. Les rabbins sont désormais

\footnotetext{
${ }^{10}$ Cette salle a pu être à ciel ouvert dans le passé. Pour une description architecturale détaillée de la synagogue, voir Fellous, 2003 et Jarrassé, 2005.
} 
sans cesse sollicités pour réciter leurs prières, recevant en échange de l'eau de vie (bûkha, en arabe dialectal), des biscuits et des fruits secs qui leur sont offerts en échange.

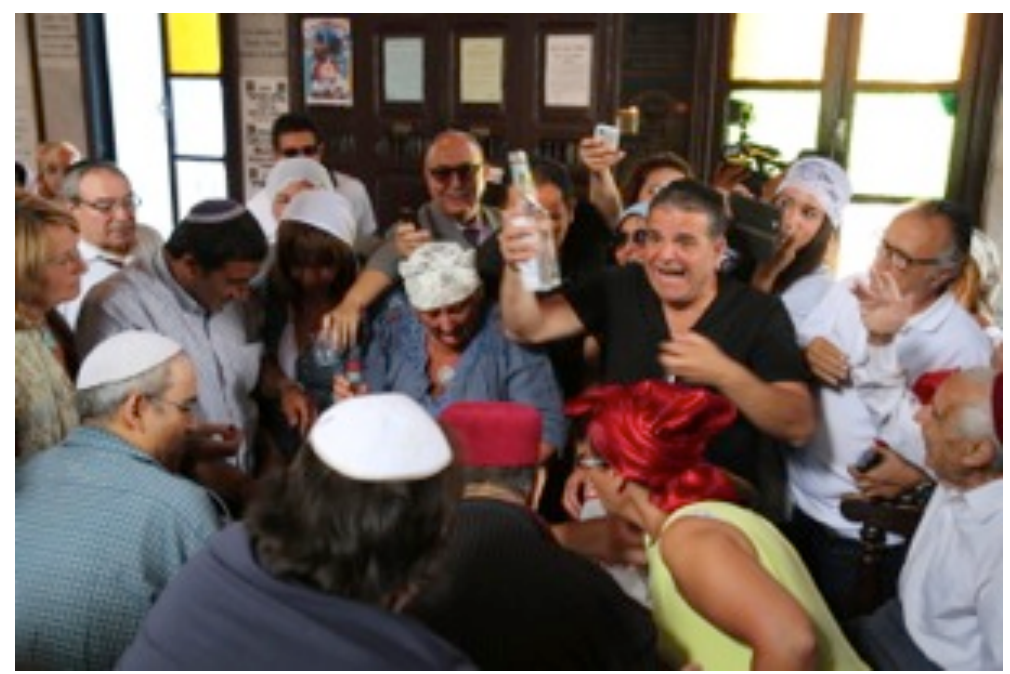

Fig. 1 : Ambiance festive dans la synagogue (C) Pénicaud

Les gens se retrouvent, souvent d'une année sur l'autre, si bien que ces retrouvailles donnent lieu à une certaine effusion. L'ambiance devient vite festive, ponctuée de blagues, de rythme de percussions (darbuka) et de chants collectifs, au fur et à mesure que les verres de bûkha circulent. Certains s'en humectent parfois le visage. Ici, un pèlerin chantant spontanément en arabe : "Où êtes-vous pèlerins, qui entrez dans la Ghriba? Et la Ghriba aujourd'hui, vous accueille et vous bénit! Poussez des youyous, pèlerins!"», ce qui est salué par une salve d'applaudissements. Quand vient l'heure de la prière, le quorum (minian) requis de dix hommes adultes est immédiatement atteint. Tournés vers Jérusalem, les hommes prient dès lors au milieu de ces clameurs assez contrastées, sous le regard des enfants qui jouent entre eux, sous les arches bleues.

A proximité, dans le fond de cette salle, se trouve une ouverture qui donne sur une citerne où un employé musulman puise cette eau « sacrée » que les visiteurs se passent sur le visage en priant, ou bien qu'ils transvasent dans des bouteilles en plastique. Une dame explique : " Quand on a un souci, qu'on a les bras coupés, qu'on ne peut pas travailler, cette eau-là nous permet de faire la chose. La bouteille, c'est si l'on a des problèmes dans le commerce ou dans la maison, alors on lave le parterre. Ou les mains, là où on a la poisse! »C'est un lieu d'interaction spontanée avec ce Tunisien musulman où l'on parle allègrement en arabe, judéoarabe, français, hébreu, ce qui souligne le multilinguisme du pèlerinage (Hagège, 2003).

La spécificité de la seconde pièce est que l'on doit se déchausser pour y pénétrer. Moins grande que la précédente (construite tardivement), cette salle de prière est un espace où la densité rituelle se déploie plus fortement : c'est le cœur du sanctuaire. Hormis le sol couvert de nattes, on retrouve le mobilier typique d'une synagogue, notamment l'estrade surélevée (bimah, en hébreu) et ornée de tissus chatoyants, où l'on «monte » lire la Torah aux fidèles. Au-dessous de ce pupitre et au centre de la pièce encadrée d'arches blanches et bleues, les nombreux brûloirs illuminent les murs d'une chaleur chatoyante. La salle est orientée comme il se doit vers Jérusalem. Le mur oriental abrite cinq armoires sacrées, rappelant l'arche d'alliance du Temple (eikhal) où sont conservés les rouleaux de la Torah. Les doubles battants de verre laissent voir des centaines d'ex-voto d'argent, offerts par les pèlerins depuis au moins le début $\mathrm{du} \mathrm{XX}^{\mathrm{e}}$ siècle. Finement ouvragés, la plupart portent des inscriptions en hébreu, de très rares sont en français. Plusieurs symboles sont récurrents : forme des Tables de la Loi, d'ornement de la Torah (rimomim), étoile de David (maghen Dawid), candélabre à sept branches (menorah), 
main à cinq doigts (khamsa), etc. De nombreux pèlerins viennent prier contre ce mur d'ex-voto, en raison de la présence de la Torah, baisant et touchant la paroi avec dévotion. Mentionnons ici l'observation faite d'une juive accompagnée d'une musulmane, toutes deux venues de région parisienne. Habituée des lieux, la première invite spontanément son amie à reproduire ses gestes, notamment le fait de prier contre ce mur d'ex-voto, en direction de Jérusalem. Rien ne permet alors de distinguer leur appartenance respective.

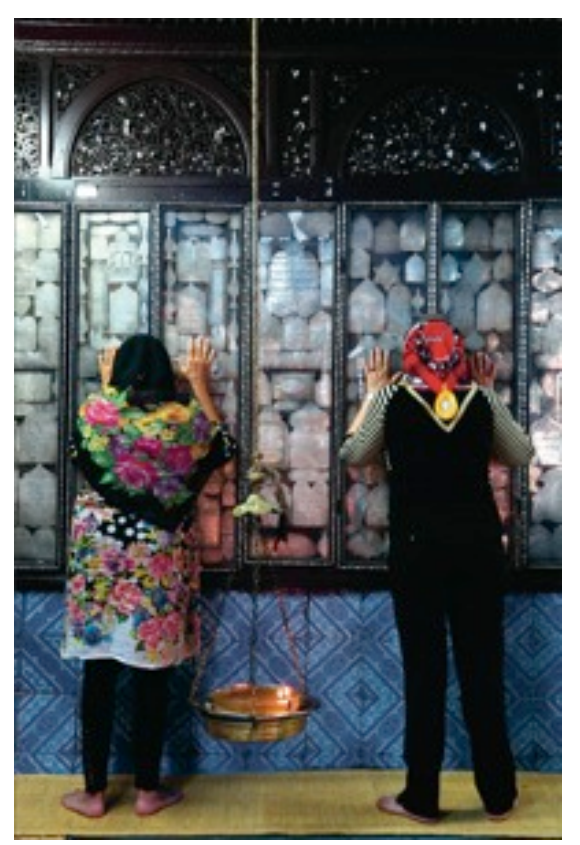

Fig. 2 : Juive et musulmane priant pieds nus vers Jérusalem

(C) Pénicaud

L'effervescence rituelle croît au fur et à mesure de l'arrivée des pèlerins. On peut distinguer d'abord un certain nombre de rituels collectifs qui dénotent une forme certaine de commensalité et de convivialité : distribution de biscuits, fumigations d'encens au-dessus de la tête contre le mauvais œil ('aïn, en arabe) ${ }^{11}$, circulation des verres de bûkha ou d'eau du puits. Ces objets circulent avec fluidité d'une main à l'autre, ce qui permet à chacun d'entrer spontanément en contact avec son voisin. Citons par exemple une dame attachant un fil rouge au poignet des pèlerins en faisant cinq nœuds pour formuler cinq vœux : «En Israël, on dit que le fil rouge, c'est pour la santé. Et comme je suis venue à Djerba cette année, j'ai voulu refaire la même chose ! »Certains demandent aussi des bénédictions à des officiants postés debout devant le mur oriental, en donnant les prénoms des personnes destinataires. L'homme se met alors à déclamer ses prières en invoquant l'intercession de Rabbi Shimon Bar Yohaï, en terminant par un «amen» collectif. Parfois, cet officiant entonne un chant que les gens reprennent en chœur et dans la bonne humeur. La convivialité est de plus en plus prégnante : on parle fort, mélangeant fièrement l'arabe et le français, quelques youyous (zagharit, en arabe) fusent spontanément et la proximité des corps est assez prononcée.

D'autres rituels s'effectuent de façon plus intime et solitaire. Le plus visible est assurément l'allumage de cierges devant les deux longs brûloirs prévus à cet effet. Il y a en permanence une vingtaine de personnes qui effectuent ce rituel, et notamment des musulmanes que rien ne distingue a priori hormis la façon de porter le voile. Notons qu'ici - contrairement à d'autres contextes religieux où la manipulation de cierges est aussi importante -, beaucoup éteignent la

\footnotetext{
${ }^{11}$ Une femme qui propose ces fumigations aux uns et aux autres, en faisant sept cercles au-dessus de la tête dans un sens puis dans l'autre, leur demande de croiser ensuite sept fois les doigts des deux mains sur le braséro, afin que les vœux soient exaucés.
} 
bougie allumée aussitôt la prière formulée, afin de l'emporter chez soi pour la rallumer « quand quelque chose ne va pas ». Sans cela, un employé vient discrètement ramasser les cierges usagés avec une spatule et un seau. Une autre pratique consiste à déposer des pièces de monnaie dans les lampes à huile suspendues au plafond, à proximité du mur principal.

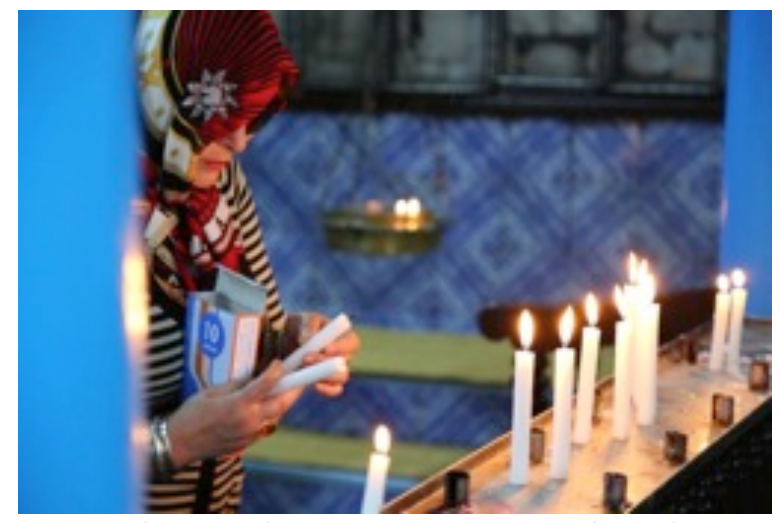

Fig. 3 : Musulmane déposant un cierge dans la synagogue (C) Pénicaud

Les vœux écrits représentent une pratique importante, si bien que le treillis de bois au-dessus des vitrines d'ex-voto de ce même mur, est littéralement parsemé de papiers roulés et coincés, comme au Mur des Lamentations à Jérusalem. Ce recours à l'écriture s'observe particulièrement autour d'un rituel propre à la Ghriba qui consiste à écrire son vœu sur un œuf de poule. Plusieurs femmes assises s'appliquent à rédiger les noms de leurs proches, penchées sur ces œufs qu'elles tiennent avec ferveur. Puis, elles se regroupent au pied du mur où se trouve la Torah, devant une ouverture rectangulaire d'environ 50 centimètres de haut, qui est généralement fermée le reste du temps. C'est l'entrée de la «crypte » de la Ghriba, le lieu où le corps de la jeune fille aurait été retrouvé si l'on en croit la légende. Sans que ce soit son lieu de sépulture, le lien avec la sainte est donc patent. Les femmes attendent leur tour avant de s'engouffrer une par une dans cet espace très étroit, en forme de tunnel d'environ six mètres de long et un peu plus d'un mètre de haut. A l'intérieur, il règne une chaleur intense à cause des nombreuses bougies allumées. Des centaines d'œufs crus et marqués jonchent le sol, beaucoup étant déjà écrasés. Pour ces femmes, pénétrer dans ce saint des saints constitue le temps fort du pèlerinage, le but de leur visite (ziyara, en arabe) où elles peuvent formuler leurs vœux les plus fervents, matérialisés par ces œufs. Le recours à l'œuf n'est pas anodin et il faut y voir un lien direct avec la fécondité. Beaucoup de vœux concernent en effet des désirs de mariage et d'enfantement. Ces vœux sont aussi formulés par des femmes relativement âgées - surtout des mères et des belles-mères - qui viennent pour leurs proches, à l'instar de cette Tunisienne qui vit à Paris depuis une quarantaine d'année : "Quand on a une jeune fille à marier, on vient et on fait l'œuf. On lui met un œuf, avec son prénom et celui de son amoureux. Et l'année d'après, ils se marient. Enfin, il faut y croire! (...) J'y crois à la Ghriba! Je ne suis pas très religieuse, mais je viens chaque année, je fais mes væux et ça se réalise, pour mes enfants, mes petitsenfants et moi-même. " Une autre habituée des lieux déclare : "Pour ma famille, mes enfants, pour des gens qui n'ont pas de bébé, qui ne sont pas mariés. La santé, la réussite, le bébé, le mariage, tout ce qu'on a au fond du cour!» Certaines ne peuvent s'empêcher d'éclater en sanglots. Sphères privée et publique sont alors imbriquées, ce qui est admis par tous.

Certaines de ces femmes sont musulmanes. Pour elles, déposer des œufs constitue aussi le rituel le plus important de leur visite. Pendant que l'une d'entre elles descend dans la crypte, son mari juif explique : "J'habite ici depuis 15 ans, dans le quartier israélite à Hara Kbira, et je suis marié avec une musulmane. J'amène le maximum de musulmans possible pour qu'ils comprennent qu'on n'est pas des êtres différents les uns des autres, on doit se côtoyer et mieux 
se connaître, pour ne pas avoir de guerres. \ Certes, les couples mixtes sont rares, mais ses propos inclusifs sont aussitôt salués par les personnes à l'entour. Si bien qu'une dame surenchérit aussitôt : "Je suis Tunisienne, musulmane et je fais la Ghriba, je fais le pèlerinage. Je l'ai fait une fois et ça m'a apporté beaucoup de bonheur. (...) Je suis comme eux. Je considère que je suis chez moi. Il n'y a pas de différence entre nous! J'ai beaucoup vécu avec des juifs et j'aime les juifs! » Et ce, en se passant sur le visage un peu d'huile provenant d'une lampe suspendue. Peu après, une juive vivant en France déclare : "Et il y a même des amis musulmans à Paris qui m'ont demandé de mettre un ouf et je leur ai mis! (sic)»

La tradition rapportée par Lucette Valensi (Valensi et Udovitch, 1984) veut que les jeunes femmes venaient déposer un œuf cru le jeudi, avant de le retrouver cuit le dimanche afin de le manger, cela favorisant de fait la fécondité tant souhaitée. Mais cela n'a plus cours, puisque nous avons constaté qu'à la fin de la journée du jeudi, à cause du surnombre et de leur accumulation, tous les œufs étaient ramassés et jetés à la poubelle par l'employé musulman. Cela pose dès lors la question de la durée du vœu qui devient donc au bout de quelques heures un déchet rituel, sans que cela n'émeuve vraiment personne. Et ce, comme si c'était la performance du rituel - l'écriture, le dépôt et la prière - qui primait plus que sa longévité matérielle, la suite devenant beaucoup moins importante.

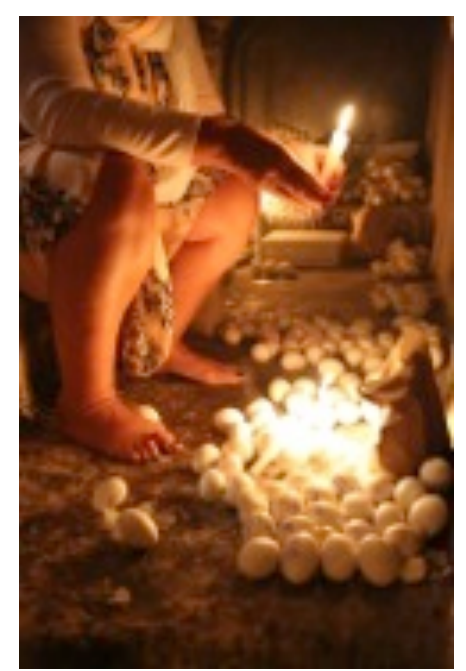

Fig. 4 : Femme déposant des oufs votifs

(C) Pénicaud

De fait, la pièce principale prend des allures d'atelier d'écriture votive. Juive ou musulmane, on écrit son vœu ou plutôt les prénoms des bénéficiaires, ce qui est une façon de les personnaliser, sur des œufs, mais aussi sur des bouts de papier ou de tissu. Ces pratiques correspondent à ce que nous appelons des « hétérographies votives », c'est à dire une façon d'inscrire son rapport au divin autre que l'écrit textuel. Ces « écritures autres » expriment et matérialisent concrètement le rapport au divin et au monde des pèlerins (Fliche et Pénicaud, 2018). Outre cette typologie de vœux, ces hétérographies incluent également l'usage croissant de la photographie et de la vidéographie, y compris pour capturer sa propre performance rituelle dans une auto-mise en scène. À tel point que la caméra, l'appareil photographique et surtout le smartphone font désormais partie prenante de l'acte rituel (Pénicaud, 2014). Ainsi, une femme descendue seule dans la crypte n'hésite pas à photographier solennellement les œufs et les cierges qu'elle y a déposés après avoir prié avec ferveur. C'est aussi une façon d'immortaliser ce moment particulier et d'en garder un souvenir, quitte à le transmettre aussitôt au destinataire du vœu par message écrit via son téléphone. Cela sert d'attestation. Une autre dame, toujours dans la crypte, n'hésite pas à téléphoner en France à l'un de ses proches pour être en « connexion » immédiate et partager cette expérience « en direct, comme si on était à Jérusalem, 
on peut venir à Djerba. On appelle bien les gens du Mur ! », explique-t-elle en montrant son téléphone. L'outil technologique est donc pleinement intégré à la performance.

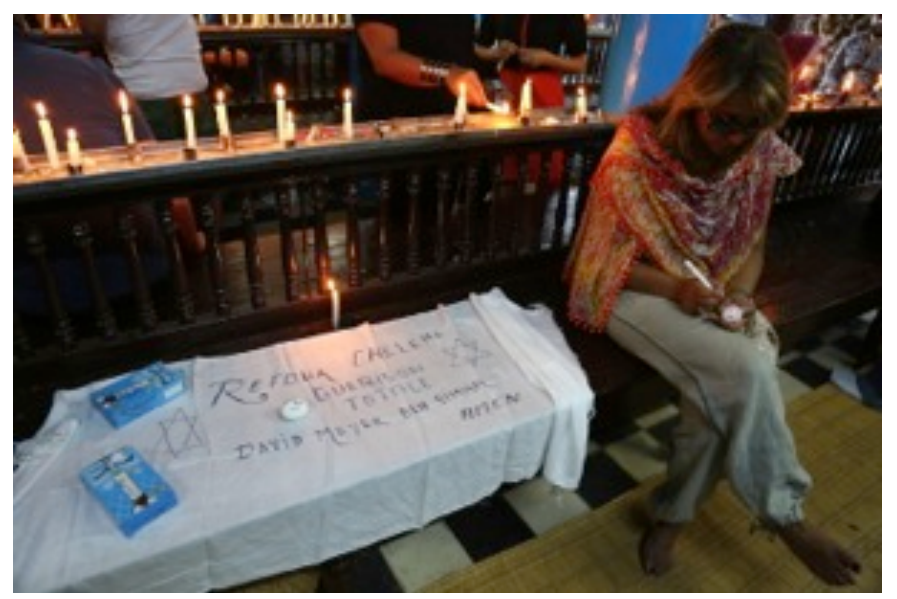

Fig. 5 : Atelier d'écriture votive (C) Pénicaud

De l'autre côté de l'allée centrale, à l'extérieur de l'espace synagogal, se trouve le caravansérail, appelé oukala (auberge), qui est un bâtiment plus important en taille. Autrefois, une part importante de pèlerins était logée sur place, mais cela n'a plus cours, au bénéfice des grands hôtels de la station balnéaire. Cet espace s'articule autour d'une vaste cour carrée d'une quinzaine de mètres de côté, bordée d'une coursive au premier étage. A cette hauteur, une multitude de fanions flanqués du drapeau tunisien traversent ladite cour, comme autant de marqueurs de revendications identitaires du type : « Nous sommes juifs et Tunisiens. » Cette cour est l'épicentre des festivités parallèles du pèlerinage. La dimension économique et marchande est représentée par les quelques échoppes où l'on peut acquérir des amulettes : khamsa (bijou en forme de main contre le mauvais œil, aussi appelé « main de Fatima » par les musulmans), pendentifs en forme de poisson, de chouette, mais aussi des bracelets, colliers, foulards, kippas, etc. Notons que les tenanciers de ces étals sont musulmans.

Un point de vente kasher (licite) permet de s'approvisionner en œufs (pour le rituel de la crypte) ou en cierges. Enfin, plusieurs échoppes proposent une restauration rapide et kasher, proposant grillades, chekchouka et autres plats traditionnels de la cuisine juive tunisienne. À la mijournée, cet espace de commensalité grouille de monde, d'odeurs et de convivialité. Et une musulmane de s'exclamer avec emphase : « Aujourd'hui, je viens pour manger le bon couscous juif!». Tout en se situant en périphérie du sanctuaire, ces activités économiques n'en demeurent pas moins constitutives du fait pèlerin et représentent même une autre centralité (Albera et Blanchard, 2015 ; Reader, 2014). Outre les dimensions sacrale et économique, un autre pilier du fait pèlerin est la fête (Dupront, 1987). L'espace de l'ancien caravansérail est animé par un groupe de musiciens jouant un répertoire connu de tous : chants et danses sont ponctués de harangues et de discours. Notons que seul les hommes se lèvent pour danser en public, ce qui est conforme au contexte du judaïsme conservateur qui prévaut et dans lequel les femmes ne dansent pas (Valensi et Udovitch, 1984).

À deux reprises, à deux jours d'intervalle, un temps fort prend lieu dans la cour du caravansérail : la vente aux enchères des rimomim, ornements de la torah qui sont placés ce jour-là au sommet de la Menara. Ce dernier est un chandelier monumental d'environ 1,60 mètre de haut, composé de cinq étages de plus en plus petits et de forme hexagonale. De couleur or, chaque étage est orné de mini-candélabres (menorah) à cinq branches et d'inscriptions hébraïques mentionnant les rabbins honorés, les patriarches bibliques, les tables de la loi et les douze tribus d'Israël. Au fil de la journée, cet objet devient un pôle d'attraction notamment 
pour les femmes qui y accrochent avec dévotion de nombreux foulards votifs. En parallèle, la solennelle vente aux enchères consiste à faire monter le prix des rimomim à plusieurs milliers de dinars. Animée par un orateur au bagout prononcé, cette longue séquence est un temps de convivialité, d'humour et de musique. C'est un honneur pour celui qui acquiert symboliquement un de ces ornements, par une offrande qui devient une donation au sanctuaire. On peut aussi obtenir le droit de porter le chandelier pendant quelques mètres.

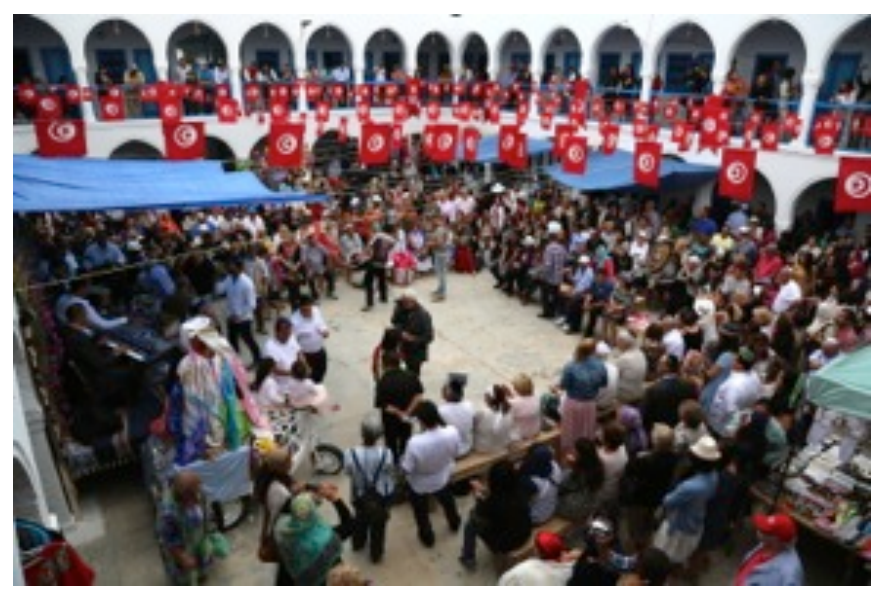

Fig. 6 : Musique, vente aux enchères et Ménara (premier plan à gauche) (C) Pénicaud

En fin de journée, la Ménara, préalablement fixée sur un chariot, est conduite en procession à l'extérieur, "vêtue comme une mariée prête à rejoindre son mari », explique l'un des organisateurs. Sous les youyous et les applaudissements, le candélabre sort du caravansérail puis des murs du sanctuaire, précédé par les musiciens. Il est de coutume que des enfants montent sur le char, brandissant des drapeaux tunisiens. Mais si la procession se rendait autrefois jusqu'au village de Hara Sghira, elle prend fin en bas de la rue où, pour des raisons de sécurité, l'itinéraire est aujourd'hui bloqué par un véhicule blindé. Un hélicoptère fend régulièrement le ciel «donnant à la scène des airs du film Apocalypse Now» comme le remarque un visiteur critique, tandis que des snipers sont postés sur le toit de la synagogue et que les services de renseignement filment la procession et chaque participant. Notons que ce cortège est observé avec curiosité par des enfants musulmans postés derrière un mur, n'ayant pas pu entrer dans l'espace du sanctuaire, tandis que certaines musulmanes prennent discrètement part à la procession. A la fin, la Ménara est solennellement escortée jusque dans la synagogue où elle est illuminée par des dizaines de cierges. 


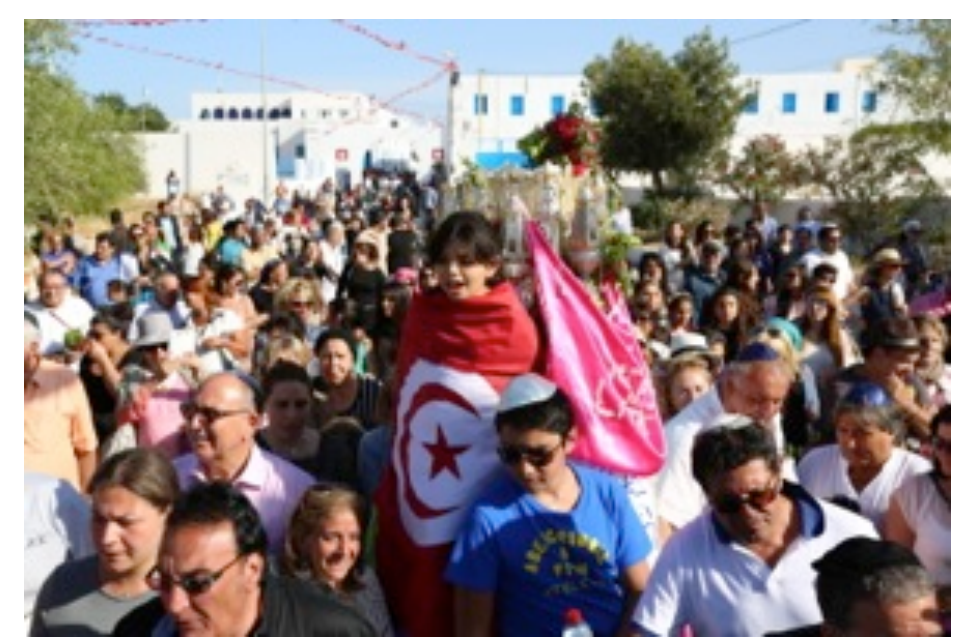

Fig. 7 : Procession de la Menara en contrebas de la Ghriba

(C) Pénicaud

Le pèlerinage s'inscrit de plus en plus dans le champ politique national et international. Pour sauvegarder l'image touristique de la Tunisie, il est important, pour le gouvernement, de montrer qu'il est à même d'assurer la sécurité de ses hôtes. L'arrivée des pèlerins de Djerba est donc encadrée et protégée de manière massive et ostensible. La présence de pèlerins avec le passeport israélien ne manque pas de susciter des réactions fortement hostiles de la part de secteurs de l'opinion publique et du monde politique tunisien, qui n'entendent avoir aucune relation avec ce qu'ils continuent d'appeler "l'entité sioniste ». De son côté, ces dernières années le gouvernement israélien s'est efforcé de décourager ses ressortissants, et plus généralement tous les juifs, de participer à ce pèlerinage. Ces enjeux politiques se matérialisent au sanctuaire, non seulement à travers l'imposant système de contrôle qui le cerne, mais également par des visites réitérées de la part de représentants politiques qui viennent apporter leur témoignage de sympathie à cette manifestation. Rien qu'en 2014, on a pu voir les ambassadeurs de France, d'Allemagne, de Malte, d'Autriche, de Serbie, du Sénégal, du Japon et des États-Unis, aux côtés des ministres tunisiens du Tourisme, du Commerce et de la Culture. Cette année-là, Amel Karboul, ministre du Tourisme, originaire de Djerba, a tenu un discours officiel devant les pèlerins. En mélangeant souvenirs personnels, réflexions générales sur l'acte pèlerin, citations de versets coraniques prônant l'entente entre les religions du Livre, elle a également abordé les questions de l'identité et de la coexistence entre religions différentes. De ce point de vue, le modèle qu'elle envisage est celui de l'âge d'or d'Al Andalous, marqué par la convivencia, " quand chrétiens, juifs et musulmans vivaient dans une paix relative, où le vivre-ensemble avait pour essence la tolérance religieuse et le respect ». Elle appelle ainsi à une nouvelle Andalousie dans la Tunisie contemporaine : «Aujourd'hui, la Tunisie qui réunit en son sein toutes les religions, qui tolère toutes les idéologies, souhaite vivre une nouvelle convivencia, celle du XXI ${ }^{\mathrm{e}}$ siècle. J'ai foi en la capacité de la Tunisie d'avoir son âge d'or. Pas seulement elle, mais toute la région. Elle ne sera pas une exception, elle montrera la voie. Notre pays est le vôtre. Vous, Tunisiens qui êtes partis pour y revenir, un peu plus souvent, un peu plus longtemps, peut-être pour tout le temps. » L'appartenance nationale est clamée haut et fort, ce que les pèlerins venus de l'étranger apprécient fortement. La dimension mémorielle est en effet constitutive de ce pèlerinage aux racines, occasion de renouer avec une identité tunisienne. Il est frappant de constater que les importants moyens de protection sont très largement plébiscités par les pèlerins qui ne tarissent pas d'éloges pour le gouvernement : "Merci à la Tunisie de nous accueillir et de nous donner cette sécurité pour qu'on puisse continuer à venir tous les ans ! », dit untel, tandis que l'animateur de la vente aux enchères s'exclame au micro : «Applaudissez la police tunisienne, je vous en supplie ! J'ai l'impression de voir un film de 
guerre, tellement ils nous aiment! Ils sont là, partout, en bas, en haut, sur le toit !»Cette surprotection les rassure et démontre selon eux la considération d'un État qui ne les a pas oubliés. Mais ces mesures relativisent l'esprit d'ouverture et tendent à promouvoir l'entre soi communautaire. L'accès au site devient très difficile notamment pour les Djerbiens et, plus généralement, les Tunisiens, car il faut montrer un passeport étranger ou une invitation distribuée à la discrétion des organisateurs, ce qui limite de fait la venue spontanée de musulmans. Certains du village ne peuvent plus facilement rentrer chez eux à cause des mesures de sécurité. Une femme rencontrée le dimanche dans la synagogue nous raconte qu'elle a été empêchée d'entrer à deux reprises, les jours précédents, « parce que je suis musulmane, c'est les autorités, je ne sais pas pourquoi ! »

\section{Conclusions}

Les éléments que nous avons dégagés dans notre analyse indiquent l'aspect paradoxal de ce sanctuaire. Nous avons vu que la synagogue est à la fois lieu saint pour des pèlerins venant surtout de loin et lieu de culte pour les riverains. Par ailleurs, les narrations qui appuient sa sainteté sont à leur tour polarisées. Au récit qui met en avant une sainteté reliant la synagogue à l'histoire biblique et à Jérusalem, centre symbolique de l'identité juive, s'en ajoute un autre qui navigue tranquillement dans les eaux d'une relative indistinction sur le plan des identités religieuses. Enfin, le pèlerinage annuel est à son tour polysémique. Il se configure depuis au moins un siècle comme une célébration collective qui réunit et ressource une communauté juive régionale (surtout d'Afrique du Nord, auparavant ; plutôt tunisienne, avec ses prolongements diasporiques de nos jours), et en même temps il admet également la participation de fidèles appartenant à une autre religion (notamment des musulmans). C'est ce conglomérat hétérogène que nous avons étudié ici, en essayant de montrer comment dans l'espace-temps de ce pèlerinage se dessine un champ qui permet aux contraires d'exister conjointement, en nourrissant une ambiguïté qui fait aussi la force et la richesse symbolique de ce sanctuaire.

En particulier, la fréquentation de la Ghriba par des musulmanes constitue un élément qui complexifie le cadre. Il s'agit, dans une très grande majorité, de femmes. Elles sont parfois invitées par un proche de confession juive, mais le plus souvent elles viennent de manière autonome. Nous avons essayé d'établir un inventaire des gestes accomplis dans l'espace-temps du pèlerinage. Les musulmanes ne participent pas aux rituels connotés sur le plan confessionnel, tels les rites qui font appel au personnel de la synagogue pour effectuer des prières, ni aux pratiques qui marquent l'appartenance communautaire (comme les enchères ou le transport de la Ménara). Elles circulent dans les deux espaces de la synagogue et du caravansérail de manière discrète et occupent aussi une position assez marginale dans la procession. Par contre, les musulmanes investissent pleinement plusieurs éléments centraux de l'infrastructure du sanctuaire, en manipulant un certain nombre d'éléments sémiotiques qui se prêtent à un usage commun, étant moins marqués d'un point de vue confessionnel. Ce sont les gestes féminins, liés aux cierges, aux œufs et à la crypte qui sont les plus partagés dans une indistinction religieuse assez flagrante.

Ces gestes matérialisent un croire en actes, diffus, indéterminé. Pour le saisir, l'anthropologie du croire esquissée par Michel de Certeau (Certeau, 1981, 1983) offre des perspectives séduisantes. Croire signifie " faire crédit » à un destinataire, en créant à la fois un partenaire différent et une restitution différée. Croire, ce n'est pas seulement dire ou penser, mais s'inscrire toujours dans un faire : on donne à un " autre », en attendant une rétribution de sa part; on demande quelque chose, on manipule des éléments matériels. Derrière la chose escomptée, il y a un interlocuteur que l'on suppose capable de répondre à la demande, sans pourtant jamais en être assuré. L'incertitude est donc consubstantielle au croire. Le croyant peut chercher à compenser l'incertitude en multipliant les interlocuteurs surnaturels. En outre, sa confiance 
s'appuie sur le fait que beaucoup d'autres croient en un certain " garant ». C'est la dimension du vraisemblable, c'est le domaine balisé par des expressions comme « l'on dit », « l'on croit », « ils croient », qui autorisent la croyance de façon plurielle, générale, neutre. Ce croire diffus et indéterminé s'articule avec le croire ordonné et spécialisé promu par les institutions religieuses, qui délimitent des contenus spécifiques dans la globalité du croyable.

Le terrain sur lequel se situent les pratiques communes aux juifs et aux musulmans dans la Ghriba relève de ce vraisemblable diffus et indéterminé, s'appuyant sur une combinatoire de dons et de dettes et sur une confiance individuelle qui se nourrit de la confiance plurielle : celle que d'autres croyants font au même répondant. Voici comment un juif tunisien installé à Paris depuis le début des années 1960 résume le pouvoir de la Ghriba : "C'est un endroit solennel! Il n'y a pas de calculs à faire, musulmans, chrétiens, juifs... S'il y a un petit problème, on a envie de pèleriner (sic), on a envie de s'évader, on a envie de faire un break ou d'exaucer des voux, la synagogue est ouverte à tout le monde. Et chacun, en fonction de ses besoins, peut faire ce dont il a envie. Des musulmans que je connais y croient autant que nous, c'est ça l'avantage! \Comme dans la plupart des autres lieux de pèlerinage, la recherche d'efficacité est le moteur de la démarche. Les gens viennent " parce que ça marche », et parce qu'ils en ont entendu parler, comme le suggère cette musulmane disant à des juifs de France : " Si vous faîtes tant de kilomètres pour venir, c'est que ça marche! Alors on vient! » Se trame alors un jeu de miroir, puisque dans l'autre sens, la fréquentation d'un sanctuaire par un " autre religieux » tend à accréditer son succès et sa renommée. Toujours est-il que c'est le pragmatisme qui l'emporte sur les considérations de légitimité ou non à franchir la frontière religieuse. On le fait d'abord par intérêt, pour bénéficier de cette efficience que l'on n'est pas sûr de trouver ailleurs. Les fidèles de religions différentes partagent - outre les lieux et les figures communes - des attentes et des désirs communs : enfanter, guérir, prospérer, etc. En d'autres termes, ce socle existentiel se matérialise à travers une série de gestes et de pratiques relevant d'une forme de grammaire rituelle commune. Cette dernière se situe dans le champ de la religiosité et non pas des religions instituées et délimitées par des dogmes souvent exclusifs. Ici, s'esquisse au contraire les contours d'une interreligiosité basée sur le partage des lieux, des figures saintes, des pratiques et des attentes. Et ce, souvent, dans le silence et la discrétion, bien loin des discours érudits des acteurs du dialogue dit interreligieux.

A côté de ces pratiques silencieuses et souvent liées à l'intimité et au secret des cœurs, fleurissent les discours de fraternité judéo-musulmane, comme cette dame s'exclamant : "Il y a une grande fraternité entre les arabes et les juifs (sic). On a grandi avec eux, on a joué avec eux, on n'a jamais eu de problèmes. Entre familles, on s'échangeait plein de choses! "; et une juive marocaine de surenchérir : "Nous étions frère et sœurs! Les musulmans croient en la jeune fille, et en ses miracles, ils viennent déposer leurs aufs et ils font des prières. Ça prouve qu'on est lié ! » Ces discours où se mêlent nostalgie et idéalisation d'un passé perdu font écho à ceux officiels, tels celui de la ministre que l'on vient de citer ou ceux des représentants du corps diplomatique. Tous cherchent à résoudre la difficile équation qui interpelle le présent inquiet et le futur incertain de ce pèlerinage. L'un des paradoxes de la territorialisation de la Ghriba consiste en une mise en abîme de l'hospitalité, fondée sur la polysémie du mot « hôte » qui désigne à la fois celui qui reçoit et celui qui est reçu. En l'occurrence, un État à écrasante majorité musulmane s'efforce tant bien que mal à accueillir un pèlerinage juif sur son territoire, malgré les crispations engendrées par le conflit israélo-palestinien, tandis que les pèlerins juifs répondent à l'appel de la Ghriba nonobstant les souvenirs douloureux du déracinement. Pour exister, ce pèlerinage a besoin de l'hospitalité de son environnement musulman, mais à son tour, il reçoit au cœur même de son saint des saints la visite pieuse de certains de ses hôtes musulmans. 


\section{RÉFÉRENCES}

Albera D., et Couroucli M (dir.), 2009. Religions traversées. Lieux saints partagés entre chrétiens, musulmans et juifs en Méditerranée. Arles, Actes Sud/MMSH.

Albera D., 2015. « La Ghriba : étrangère, solitaire et mystérieuse », in Albera D., Pénicaud M. et Marquette I. (dir.), Lieux saints partagés. Arles, Actes Sud/Mucem, p. 140-143.

Albera D., 2017. "Toward a Reappraisal of Ambiguity: In the Footsteps of Frederick W. Hasluck », in Zarcone T. et Hobart A. (dir.), Pilgrimages and Ambiguity: Sharing the Sacred. Londres, Kingtson Publishing, p. 23-43.

Albera D., et Blanchard M. (dir.) 2015. Pellegrini del nuovo millennio, Messine, Mesogea.

Albera D. et Pénicaud M., (dir.), 2017. Coexistences. Lieux saints partagés en Europe et en Méditerranée. Arles, Actes Sud/MNHI

Albera D., Pénicaud M. et Marquette I. (dir.), 2015. Lieux saints partagés. Arles, Actes Sud/Mucem.

Allagui A., 2016. Juifs et Musulmans en Tunisie : des origines à nos jours. Paris, Editions Tallandier/Projet Aladin.

Amaury, V. 1896, A travers le monde, Paris.

Allali B., 2014. Les juifs de Tunisie : un autre regard. Éditions Bernar Allali.

Aubin-Boltanski, Emma, «La Vierge, les chrétiens, les musulmans et la nation », Terrains, 51, Paris, 2008, p. 10-29.

Badone E. et Roseman, S., (dir.), 2004, Intersecting Journeys. The Anthropology of Pilgrimage and Tourism, Urbana \& Chicago, University of Illinois Press.

Barkan E. et Barkey K. (dir.), 2014. Choreographies of Shared Sacred Sites. Religion, Politics, and Conflict Resolution. New-York, Columbia University Press.

Ben-Ami I., 1990. Culte des saints et pèlerinages judéo-musulmans au Maroc. Paris, Maisonneuve et Larose.

Bowman G. (dir.), 2012. Sharing the Sacra: The Politics and Pragmatics of Intercommunal Relations around Holy Places. New York, Berghahn.

Carpenter-Latiri D., 2012. «The Ghriba in the Island of Jerba (or Djerba) or the re-invention of a shared shrine as a metonym for a multicultural Tunisia » in Bowman G. (dir.), Sharing the Sacra: The Politics and Pragmatics of Intercommunal Relations Around Holy Places. New York, Berghahn, p. 118-138

Certeau de, M., 1981. "Une pratique sociale de la différence : croire », in Faire croire. Modalités de la diffusion et de la réception des messages religieux du XIIe au XVe siècle. Actes 
de table ronde de Rome (22-23 juin 1979), Rome, École Française de Rome, p. 363-383. (Publications de l'École française de Rome, 51).

Certeau de, M., 1983. "L'institution du croire: note de travail », Recherches de Science Religieuse. 71, p. 61-80.

Conord S., 2010. « Le pèlerinage Lag ba Omer à Djerba (Tunisie). Une forme de migration touristique ", in Boissevain K. (dir), Socio-anthropologie de l'image au Maghreb. Nouveaux usages touristiques de la culture religieuse. Paris, L'Harmattan, p. 105-116.

Depret et Dye, 2012. Partage du sacré. Transferts, dévotions mixtes, rivalités interconfessionnelles. Fernelmont, Editions EME.

Deshen S., 1997. «Near the Jerba Beach: Tunisian Jews, an Anthropologist, and Other Visitors », Jewish Social Studies, New Series, Vol. 3, 2, pp. 90-118

Dupront A., 1987. Du Sacré. Croisades et pèlerinages. Images et langages. Paris, Paris, Gallimard.

Fellous S., (dir.), 2003. Juifs et musulmans en Tunisie, fraternité et déchirements. Paris, Somogy éditions d'art et Société d'Histoire des Juifs de Tunisie.

Fellous S., 2003. « Architecture des synagogues de Tunisie. Essai de typologie », in Fellous S. (dir.), Juifs et musulmans en Tunisie, fraternité et déchirements. Paris, Somogy éditions, p. 371390.

Fliche B. et Pénicaud M., 2018, «Hétérographies votives au monastère de Saint-Georges (Büyükada, Istanbul) », Gradhiva, 2018, à paraître.

Gendre, F., 1908. « L'île de Djerba », Revue tunisienne. 15, p. 60-79.

Hasluck F., 2000 (1929). Christianity and Islam under the Sultans. Istanbul, Isis Press.

Hagège, C. 2003. «Le multilinguisme dans la sphère judéo-tunisienne », in Fellous S. (dir.), Juifs et musulmans en Tunisie, fraternité et déchirements. Paris, Somogy éditions, p. 297-308.

Jarrassé D., 2005. «Fonctions et formes de la synagogue : refus et tentation de la sacralisation », Revue de l'histoire des religions [En ligne], 4, mis en ligne le 14 janvier 2010, consulté le 10 mars 2017. URL : http://rhr.revues.org/4216 ; DOI : 10.4000/rhr.4216

Pénicaud, M., 2014. «Filmer les pèlerinages et le religieux en mouvement », ThéoRèmes. Enjeux des approches empiriques des religions 7. doi: 10.4000/theoremes.673

Podselver, L., 2001. « Le pèlerinage tunisien de Sarcelles », Socio-anthropologie [En ligne] 10, URL : http://socio- anthropologie.revues.org/157

Reader I., 2014. Pilgrimage in the Marketplace. Londres et New York, Routledge.

Slouschz N., 1909. Un voyage d'études juives en Afrique, Paris, Imprimerie Nationale. 
Taïeb J., 2000. Sociétés juives du Maghreb moderne (1500-1900) : un monde en mouvement. Paris, Maisonneuve \& Larose.

Turner V. et Turner E., 1978, Image and Pilgrimage in Christian Culture: Anthropological perspectives, Oxford, Basil Blackwell.

Valensi L. et Udovitch A. L., 1984. Juifs en Terre d'Islam : les communautés de Djerba. Montreux, Éditions des archives contemporaines.

Véhel J. 1930. « Pèlerinages nord-africains », L'univers israélite, 16/05, p. 170-172 ; 23/05, p. 208-209.

Voinot L., 1948. Pèlerinages judéo-musulmans du Maroc, Paris, Larose.

Zafrani H., 1990 (1983). Deux Mille Ans de vie juive au Maroc. Paris, Maisonneuve et Larose.

Zarcone T. et Hobart A., 2017. Pilgrimages and Ambiguity: Sharing the Sacred. Londres, Sean Kingston Publishing. 